\title{
VOLTAIRE CONTRA EL ATEÍSMO Y
}

\author{
CONTRA SÍ MISMO (1761-1770)
}

\section{VOLTAIRE AGAINST ATHEISM AND HIMSELF \\ (1761-1770)}

\author{
ADRIÁn RATTO" \\ Universidad de Buenos Aires / Consejo Nacional de Investigaciones \\ Científicas y Técnicas
}

Resumen: El objetivo de este trabajo es mostrar que la polémica en torno al ateísmo que tuvo lugar en los años 60' entre Voltaire y la coterie holbachique empujó al filósofo francés a suscribir ideas cuya relación con el resto de su obra y con el combate que en esos años libraba en favor de la tolerancia es problemática. Esto esclarece la llamativa posición adoptada por Voltaire frente a la disolución en 1764 de la Compañía de Jesús. Por otra parte, el trabajo arroja luces sobre el alcance de la revolución epistemológica que el filósofo pretendía generar en el campo de la historiografía.

Palabras clave: Voltaire, Ateísmo, Dios, Tolerancia, Historia.

AвSTRACT: The aim of this paper is to show that the polemic around atheism, which occurred in the 1760s between Voltaire and the coterie holbachique pushed the French philosopher to subscribe to ideas whose connection with the rest of his work and with

\footnotetext{
* Investigador del Consejo Nacional de Investigaciones Científicas y Técnicas (CONICET). Se desempeńa como docente en la materia Filosofía de la historia (departamento de Filosofía, Facultad de Filosofía y Letras, Universidad de Buenos Aires). Dirección postal: Av. Luis María Campos $3813^{\circ} \mathrm{A}$, Ciudad Autónoma de Buenos Aires, Argentina. E-mail: ga_ratto@yahoo. com.ar.
} 
the fight that was taking place in those years in favor of tolerance is problematic. This clarifies the striking position adopted by Voltaire regarding the dissolution of the Society of Jesus in 1764 . On the other hand, the work sheds lights on the scope of the epistemological revolution that the philosopher intended to generate in the field of historiography.

KeYwords: Voltaire, atheism, God, tolerance, history

\section{Introducción}

Prohibida por el Parlamento de París el 6 de agosto de 1762, la Compañía de Jesús fue disuelta finalmente en Francia en 1764 por Luis XV. Entre les philosophes, Denis Diderot y Jean le Rond d'Alembert aplaudieron la decisión ${ }^{1}$. Voltaire, en cambio, se mostró dubitativo ${ }^{2}$. En una carta a d'Alembert del 14 de abril de 1764 señala que «los jesuitas eran necesarios» (Voltaire, 1832, 399) 3 . Esta declaración resulta sorprendente pues fue redactada por alguien que se encontraba en medio de un intenso combate contra las religiones reveladas.

El objetivo de este trabajo es arrojar luces sobre la discordancia entre esas palabras de Voltaire y su combate filosófico-político contra las religiones,

\footnotetext{
1 «Aquí, mi querida amiga la carta de defunción de los jesuitas [...]. Heme aquí librado de un gran número de peligrosos enemigos», dice Diderot en una carta del 8 de agosto de 1762 a Sophie Volland, aludiendo al decreto del Parlamento que prohibía a la Compañía de Jesús. «Sumidos al despotismo en el interior de su institución, eran los más viles promotores de ese orden para la sociedad en su conjunto", se puede leer algunas líneas después (Diderot, 1877, 98-99). D’Alembert, por otra parte, saluda la expulsión de la orden jesuita diciendo que los magistrados que la llevaron a cabo eran "personas ilustradas», personas que se encontraban "a la altura de una época» donde la razón avanza y el fanatismo y las disputas religiosas se vuelven cada vez más despreciables ( $c f$. D’Alembert, 1765, 137-138).

2 En 1766 Peter Gay publicó un célebre trabajo, The Enlightenment: the Rise of Modern Paganism, donde presentaba la filosofía del siglo de las Luces como anticristiana y reformista. Esa interpretación fue puesta en tela de juicio en los últimos ańos por trabajos que han intentado demostrar la importancia de la religión tanto entre les philosophes como entre sus críticos. Acerca del lugar que la religión ocupó en el siglo de las Luces, véase Barnett, 2003; Curran, 2012; Sorkin, 2006 y Haakonssen, 2006.

${ }^{3}$ Voltaire, incluso, ofrece asilo en su residencia de Ferney a un jesuita, el padre Adam, luego de la disolución de la Compañía. A propósito de la relación entre Voltaire y Antoine Adam, véase Lambert, 1992. Dos pinturas de Jean Huber, un familiar de Voltaire que también residía en la finca de Ferney en esa época, ilustran esa relación: «Voltaire jouant aux échecs avec le père Adam» (1764) y «Un dîner de philosophes» (1772).
} 
particularmente durante los ańos 60', un momento donde su lucha contra las religiones reveladas se radicaliza. Para alcanzar ese propósito es necesario analizar la posición de Voltaire frente al ateísmo. Se demuestra que las críticas de Voltaire al ateísmo lo llevaron en la misma época de la carta mencionada a adoptar posiciones cuya articulación con el resto de su obra es problemática.

La estructura del trabajo es la siguiente: en primer lugar (2), se revisará la polémica entre Voltaire y la coterie holbachique acerca del ateísmo; en segundo lugar (3), se examinarán las tensiones que esa polémica genera en la filosofía del autor de la Henriade; a continuación (4), se analizará el lugar que el ateísmo ocupa en otro trabajo de la época, la Philosophie de l'histoire (1765). Esto último arrojará, por otro lado, algunas luces acerca del alcance de la revolución epistemológica que Voltaire pretendía generar en el campo de la historiografía.

\section{Voltaire y la coterie holbachique: una relación problemática}

El 2 de mayo de 1760 se representó con éxito en la Comedia francesa la obra Les philosophes, dirigida por Charles Palissot. El autor lanzó a través de esa pieza una desenfrenada crítica a algunos destacados enciclopedistas: Claude-Adrien Helvétius, Denis Diderot y Jean Jacques Rousseau, entre otros ${ }^{4}$. La polémica que suscitó la obra se inscribe en un contexto de proliferación de críticas antifilosóficas, muchas de las cuales se habían desencadenado a partir de la publicación en 1751 del primer volumen de la célebre Encyclopédie, editada por Jean le Rond d'Alembert y Denis Diderot ${ }^{5}$. Hacia 1760, Francia se encontraba, por otra parte, en una situación delicada como consecuencia de la Guerra de los Siete Años y la sociedad estaba aún conmocionada por el atentado de Damiens contra el rey Luis XV. En ese marco la obra de Palissot recogía muchas de las críticas que

\footnotetext{
${ }^{4}$ La pieza Les philosophes no fue el único trabajo en el que Palissot atacó a los enciclopedistas. En efecto, en 1755 había hecho representar en Lunéville, en la corte del rey Stanislas, Le cercle ou les originaux, donde criticaba principalmente a Rousseau. Dos ańos después, en 1757, publicó unas Petites lettres sur les grands philosophes, donde atacó una vez más a los enciclopedistas, particularmente a Diderot. Los cuestionamientos de Palissot a les philosophes continuaron, por otra parte, luego de 1760. El encono con el que Palissot atacó a los filósofos fue para muchos una sorpresa, ya que el autor de Les philosophes había sido durante muchos años un admirador de Voltaire.

5 Acerca de la polémica entre el partido de Les Philosophes y sus críticos, véase Ferret, 2007; Masseau, 2000, particularmente el capítulo 2: «Les luttes stratégiques», 109-198.
} 
se hacían a les philosophes, a quienes se consideraba responsable de los difíciles momentos que atravesaba la nación.

Los críticos atacaban a los enciclopedistas como una unidad, un grupo homogéneo. Sin embargo, les philosophes no constituían un grupo sin fisuras. Entre otras diferencias ideológicas se pueden mencionar las que existían entre Voltaire y las personas que asistían al salón literario del barón de Holbach, Denis Diderot, Claude-Adrien Helvétius y Grimm, entre otros (la coterie holbachique). Es verdad que a comienzos de los años 60' tanto la coterie como Voltaire luchaban contra las religiones reveladas, es decir, impulsaban un programa similar. No obstante, el problema de la existencia de Dios pronto puso de relieve las diferencias entre las partes y generó tensiones, que se fueron acentuando con el correr de la década ${ }^{6}$. La tormenta entre los ateos de la coterie holbachique y el filósofo francés comenzó a formarse a mediados de los años 60', con la publicación del Christianisme dévoilé (1766), del barón de Holbach. Las críticas radicales a la religión allí expresadas inquietaron a Voltaire que se quejó en los márgenes del ejemplar que él poseía por el trato dispensado a la misma. En una carta a $\mathrm{M}^{\mathrm{me}}$ de La Tour du Pin de Saint-Julien del 15 de diciembre de 1766 afirma, luego de criticar cuestiones de estilo del trabajo: «ese libro es completamente contrario a mis principios. Ese libro conduce al ateísmo que yo detesto» (Voltaire, 1833a, 475).

Voltaire respondió un año después (1767) a través de un trabajo que lleva por título Homélies, compuesto por cuatro capítulos llamados irónicamente «homilías». En la primera homilía, dedicada al ateísmo de los integrantes del salón literario del barón de Holbach, no duda en insultar y llamar «monstruos» a los ateos y ponerlos en el mismo lugar que a los fanáticos. Pero, más allá de las injurias, presenta tres argumentos contra el ateísmo. En primer lugar (1), esgrime un argumento lógico-metafísico acerca de la existencia de Dios. Una obra, dice, tiene que tener un responsable, por lo tanto, concluye, el orden del mundo y de la naturaleza prueban la existencia de Dios: «el curso de los astros y de toda la naturaleza demuestran la existencia de su creador» (Voltaire, 1879a, 316). Inmediatamente se plantea dos posibles contra-argumentos u objeciones de los «discípulos de Estratón y Zenón», es decir, los materialistas ateos de la coterie: a) Dios no es necesario, porque el movimiento es esencial a la materia (cf. 316); b) la existencia del mal en el mundo prueba la inexistencia de Dios (cf. 319). Frente

${ }^{6}$ La preocupación de Voltaire por el ateísmo no era nueva, se remontaba a los años 50', al período de su estancia en Potsdam en la corte de Federico II de Prusia, donde se había opuesto al materialismo ateo de Julien Offray de La Mettrie. Ver infra nota 11. 
a la primer objeción (a) responde (a.i) que «los sabios consideran que la materia es indiferente al movimiento y al reposo» (316); que (a.ii) aun aceptando que el movimiento es esencial a la materia no es necesario negar la figura de Dios y que (a.iii) el ejemplo de los dados, que arrojan diferentes combinaciones al ser lanzados en diferentes ocasiones, es insuficiente para probar que el mundo no requiere un artesano ( $c f .317)$. Con respecto a la segunda objeción (b), dice que, puesto que ya ha demostrado la existencia de Dios y que pensar en la existencia de un «dios malvado» es un absurdo desde el punto de vista lógico-metafísico, se debe reconocer -incluso aceptando la existencia del mal en el mundo- la existencia de «un Dios justo», un «Dios remunerador y castigador» (321). El segundo argumento (2) contra el ateísmo es un argumento ético-político: es necesario reconocer la existencia de un dios remunerador y castigador, puesto que «ninguna sociedad puede subsistir sin recompensa y sin castigo» (322). El criterio para afirmar la existencia de Dios en este último caso no proviene de la lógica o la metafísica, sino de la utilidad social. Para apoyar su afirmación, pone como ejemplo los horrores de la época de Nerón, la sangre derramada en una sociedad donde "dominaba el ateísmo» (323). El ateísmo, concluye, «puede causar tanto mal como las supersticiones más groseras» (323) y se refiere al ateo como un "impostor», un «monstruo», un «hombre ruin" y "sanguinario» (324). Finalmente (3), presenta un tercer argumento de carácter gnoseológico. El ateísmo, dice, no es un conocimiento pleno, seguro, sobre el cual el espíritu pueda reposar con tranquilidad como lo hace sobre «el conocimiento geométrico» (327). ¿No es un «pseudoconocimiento» apoyado por pasiones violentas?, se pregunta. Inmediatamente afirma que fueron en realidad los teólogos quienes, deformando la religión, «crearon a los ateos». Las absurdas máscaras que pusieron a la divinidad llevaron a muchos a negar la existencia de Dios, explica. El ateísmo es para Voltaire, sencillamente un error, un falso conocimiento ${ }^{7}$.

\footnotetext{
7 Ese mismo año en Questions sur les miracles (1767) ataca la teoría acerca de la generación espontánea de la vida, defendida por el católico inglés John Needham (1713-1781) en su An account of some new microscopical discoveries (1745). Voltaire sabía desde que había recibido la visita de Etienne Noël Damilaville en Ferney en 1765 -Damilaville, que fue también un enciclopedista, era desde 1761 un intermediario entre la coterie y Voltaire- que ése era el fundamento del materialismo ateo de la coterie. El filósofo francés afirma en las Questions que la teoría de Needham es falsa porque así lo demuestra un experimento de un científico italiano, Lazzaro Spallanzani, y además, agrega, que no puede ser verdadera porque es absurda, ya que niega que la generación tenga una causa (cf. Voltaire, 1879c, 393). De esta manera intenta una vez más a través de un argumento de autoridad y una petición de principio demostrar que el ateísmo es un falso conocimiento.
} 
Los cruces no terminaron con estos textos. En una breve reseña del trabajo publicada en 1767 en la Correspondance littéraire, dirigida por uno de los integrantes de la coterie, Grimm, se afirma que las Homélies de Voltaire son un trabajo superficial y se habla del autor con ironía como un "capuchino» (cf. Grimm, $1879,345)$. Ese mismo año, 1767, Voltaire publica otros trabajos en los que ataca a los ateos, como L'examen important de Milord Bolingbroke y Lettres à S. A. Mgr le prince de ${ }^{* * *}$ sur Rabelais et sur d'autres auteurs accusés d'avoir mal parlé de la religion chrétienne. El enfrentamiento continuó en 1770 con la publicación del Système de la nature, donde Holbach ataca directamente al autor de la Henriade. Voltaire no tardó en responder a través del trabajo Dieu. Réponse au Système de la nature, que publica ese mismo año y cuyas líneas centrales retomaría poco después en la entrada Dieu de las Questions sur l'Encyclopédie (1770). En ambos trabajos reproduce los argumentos lanzados en 1767. En 1775, Voltaire retoma una vez más la lucha contra el materialismo ateo en una obra de ficción, Histoire de Jenni ou le Sage et l'athée, donde los ateos pervierten al buen Jenni.

\section{Los límites de la campaña contra l'Infâme}

En 1762 un viajero que procedía de Languedoc se detuvo en Ferney y relató a Voltaire un hecho que había conmocionado a la ciudad de Toulouse. Allí, en el mes de marzo de ese mismo ańo, el comerciante Jean Calas había sido sometido a torturas, colgado y quemado por orden del Parlamento de la ciudad. A Calas se lo había condenado por habérselo encontrado culpable de la muerte de su hijo, quien pensaba convertirse al catolicismo. Voltaire, sin embargo, sospechaba que el motivo real era el protestantismo de Jean Calas, es decir, que se trataba de un caso de intolerancia religiosa. Por esa razón, emprendió la rehabilitación de Calas ante los tribunales, con resultado positivo (el proceso fue revisado y la viuda y las hijas de Jean Calas, liberadas de todo tipo de acusación e indemnizadas); además preparó un trabajo que se publicaría un año después, el Traité sur la tolérance (1763), donde aboga por la tolerancia religiosa ${ }^{8}$. El caso Calas no fue el único en el que Voltaire participó activamente. También lo haría en los casos del protestante Sirven, logrando la absolución de la pena a la que se lo había condenado, y del caballero de La Barre. No pudo en el último caso evitar la ejecución de la pena, la sentencia fue ejecutada en Abbeville el 1 de julio de 1766, pero redactó

8 Para una visión de conjunto acerca del problema de la tolerancia en el siglo XVIII, véase Grell y Porter, 2000. Véase también Trousson, 1993. 
una serie de trabajos, entre ellos una Relation de la mort du Chevalier de la Barre (1766), donde repasa los momentos del proceso que culminó con la muerte del caballero de la Barre, con el fin de que Europa no olvide el atroz suceso.

Sin embargo, la escalada en la lucha contra el ateísmo marcó en los mismos años 60' los límites de la campańa de Voltaire por la tolerancia. El intercambio de críticas con los ateos de la coterie llevó al filósofo francés a colocarse en las puertas de la intolerancia al señalar en 1769, en el trabajo Dieu et les hommes, que pensaba que no se debería tolerar que se negara la existencia de Dios:

Aunque me enorgullezco de ser muy tolerante, me inclinaría a pensar que se debería castigar a aquellos que dicen en la actualidad: «Señores, señoras, Dios no existe. calumniad, mentid, engañad, robad, asesinad, envenenad, todo es igual mientras seáis los más fuertes o los más hábiles». Es claro que ese hombre es muy peligroso para la sociedad [...] (Voltaire, 1879b, 133).

Ya en 1767, en las Homélies no había dudado, como hemos señalado, en llamar «monstruos» a los ateos. Por otra parte, en una carta a M. Saurin del 10 de noviembre de 1770 escribía que el libro de Holbach era, a causa del ateísmo que se desprendía de él, un "trabajo maldito», "un pecado contra la naturaleza» (Voltaire, $1833 \mathrm{~b}, 481)^{9}$. En ese marco no es sorprendente que los mismos devotos citaran a Voltaire para atacar a los incrédulos. Es el caso, por ejemplo, del abate Chaudon, quien paradójicamente lo cita en la entrada Dieu de su Dictionnaire anti-philosophique (1767).

Pero, la defensa de la tolerancia era, en realidad, para Voltaire, parte de un programa filosófico-político más amplio, que también fue afectado por la polémica con los ateos de la coterie. En 1761, Voltaire comenzó a firmar sus cartas con la frase «destruid al infame» (écrasez l'infâme). La fórmula «destruid al infame» es un llamado a aniquilar la superstición y el fanatismo, a combatir las pasiones religiosas, capaces de trastornar a las multitudes y llevarlas a cometer actos atroces como la masacre de San Bartolomé, y la intolerancia institucional como la que

\footnotetext{
9 Es verdad que Voltaire modera por momentos su posición al aceptar que puede llegar a darse en alguna ocasión el caso de la existencia de un ateo virtuoso, sin embargo seńala que eso sólo podría alcanzarse en el plano privado y en el marco de una sociedad donde no reinara el ateísmo ( $c f$. Voltaire, 1879a, 328-329). Voltaire considera que una sociedad dominada por el ateísmo no podría llegar a ser una buena sociedad desde el punto de vista moral y político.
} 
llevaba adelante la Inquisición en España. En esa época Voltaire emprende desde su finca en Ferney, tras diferentes ataques a les philosophes y casos de intolerancia religiosa, su lucha más virulenta contra las religiones reveladas. A través de diferentes medios, como la defensa de personas perseguidas por sus ideas religiosas o la elaboración de tratados, libelos y piezas de teatro se enfrenta al clero y sus relatos. Pero, ¿cuáles fueron las causas de esa empresa? Esa lucha se asienta, en realidad, en una metafísica que ya estaba presente en su juventud. Si Voltaire no emprendió antes ese combate fue meramente por cuestiones coyunturales (persecución ideológica en la Francia del siglo XVIII, censura, etc.). Se trata de la metafísica de la época de Cirey, la metafísica que a la luz de los trabajos de Newton elaboró al lado de la marquesa Émilie du Châtelet y sistematizó en 1734 en su Traité de métaphysique (publicación póstuma). Allí, presenta a Dios como un ser puro y eterno, responsable del orden del mundo. De sus argumentos no se desprende más que eso. El Dios de Voltaire no se mezcla en la vida de los hombres como el Dios de las religiones reveladas. «Es absurdo decir que Dios es justo o injusto», exclama. Es insensato, agrega, «reprocharle que los hombres abusen de su libertad para destruirse entre ellos mismos, que tengan enfermedad, pasiones crueles, etc.» (Voltaire, 1879d, 201). La misma idea era expresada en sus Letters Concerning the English Nation (1733, publicadas en 1734 en francés, Lettres philosophiques) en un relato ficticio entre el autor y un cuáquero en el que éste último dice: "pensamos que el nombre del Altísimo no debe prostituirse en las disputas miserables de los hombres» (Voltaire, 1964a, 23). Sobre esa distancia entre la divinidad y los hombres se apoyan sus críticas a las supersticiones y los dogmas que intentan establecer un contacto entre la divinidad infinita y omnipotente y los individuos. «La idea de un dios hombre es monstruosa, pues la distancia de Dios al hombre es infinita», dice algunos años más tarde en la entrada Divinité DE JÉsus del Dictionnaire philosophique portatif (1764) (Voltaire, 1964b, 167).

La escalada en el combate contra el ateísmo no solo llevó a Voltaire a rozar la intolerancia, como creemos haber demostrado, sino que también debilitó su lucha contra el infame y generó tensiones en el plano de sus ideas metafísicas. En efecto, ya en su Traité sur la tolérance afirmaba que para el género humano «es mejor ser subyugado por todas las supersticiones posibles (...) que vivir sin religión» (Voltaire, 2007, 143). Asimismo, en la entrada AтÉE, АтнÉisme del mencionado Dictionnaire philosophique sostiene que «en una ciudad civilizada es infinitamente más útil tener una religión, incluso mala, que no tener ninguna» (Voltaire, 1964b, 55) y en la segunda parte de las Homélies se muestra incluso indulgente con cierto tipo de supersticiones (Voltaire, 1879a, 330 y ss.). En ese trabajo no duda incluso en afirmar que el ateísmo puede ser tan 
funesto para el género humano como el fanatismo $(c f .329)^{10}$. Esto significa, sin dudas, un paso atrás en su lucha contra la superstición y el fanatismo. Por otra parte, las críticas al materialismo ateo de la coterie lo condujeron, como se mostró en el apartado anterior, a aceptar una idea de la divinidad que antes había rechazado, la idea de un Dios que remunera y castiga (cf. Voltaire, 1879a, $322)^{11}$. Ahora bien, un dios capaz de juzgar a los individuos es un dios que tiene injerencia en el mundo de los hombres. Esta idea genera tensiones en la filosofía de Voltaire, dada la distancia que en su obra separa a la divinidad de los hombres, una idea a la que nunca renuncia. En las mismas Homélies afirma que «el infinito separa a Dios del hombre» (Voltaire, 1879a, 330).

\section{Ateísmo e historia}

En 1742 Voltaire publicó el trabajo Remarques sur l'histoire y dos años después, en 1744, Nouvelles considerations sur l'histoire. En estos textos presenta un programa para la renovación de la historia. El programa formaba parte de su proyecto de introducir a Newton en Francia. Con ese fin había escrito los Eléments de la philosophie de Newton (1738), mientras la marquesa Émilie du Châtelet, junto a quien vivía en Cirey, traducía al francés la Philosophia Naturalis Principia Mathematica de Newton (cf. Pomeau, 2001). El trabajo de Newton había sido publicado en Londres en 1687, pero los franceses eran aún devotos de la física de los torbellinos de Descartes. El fin del autor de la Henriade, que había entrado en contacto con las obras de Newton, Locke y Bacon, entre otros, durante su exilio en Inglaterra, no era sólo modificar la interpretación de sus compatriotas acerca del mundo físico, sino también producir una revolución desde el punto de vista de la metodología del conocimiento. En este marco se inscribe su intención de acercar la historia a los métodos de la física experimental: «Quizá pronto ocurra en la manera de escribir historia, lo que ha sucedido en la física. Los nuevos descubrimientos han vuelto obsoletos

${ }^{10}$ El 26 de agosto de 1768 escribe al marqués de Villevielle: «querido marqués, no hay nada bueno en el ateísmo» (Voltaire, 1833b, 159).

11 La idea del dios «remunerador y castigador» aparece por primera vez en 1752, en la época de la estancia en la corte de Federico II, en un manuscrito titulado Athée, que anticipa las entradas Athée, Athéisme del Dictionnaire philosophique (1764) y de las Questions sur l'Encyclopédie (1770). En ese momento Voltaire estaba preocupado por el materialismo ateo de La Mettrie. A propósito de la estancia de Voltaire en Prusia y los detalles de la polémica, véase Magnan, 1986. 
los antiguos sistemas [...]. Se querrá conocer al género humano con el mismo rigor alcanzado en la filosofía natural» (Voltaire, 1957, 46) ${ }^{12}$.

Acercar la ciencia a la historia significaba para Voltaire, como se desprende de los dos trabajos mencionados, dos cosas: a) ajustar el relato histórico a los "hechos", dejando de lado «los oráculos» y «las fábulas antiguas»; b) ampliar los límites del campo de investigación. La entrada Histoire, que redactó algunos años después, en 1765, para el volumen octavo de la Encyclopédie, resume este programa: «Se exige a los historiadores modernos más detalles, hechos registrados, referencias bibliográficas, datos precisos, más atención a los usos, las leyes, las costumbres, el comercio, las finanzas, la agricultura, la demografía. En historia, como en matemáticas y física, el campo de trabajo se ha expandido notablemente» (Voltaire, 1765, 225). Voltaire se propuso escribir historia de manera científica, apoyando el relato en hechos, testimonios y registros públicos, y tomando distancia respecto de las historias romanesques y las fábulas. Esto lo llevó a alejarse de aquellos que, como Géraud de Cordemoy (1626-1684), habían afirmado que el historiador tenía que ocuparse de la belleza y la claridad del estilo antes que de la veracidad de la información acerca del pasado ( $c f$. Cordemoy, 1691, 68-69), pero también de aquellos que, como Claude Fleury en su Histoire ecclésiastique (1691) o Charles Rollin en Histoire romaine depuis la fondation de Rome jusqu'à la bataille d'Actium (1738), confundían la historia y la religión o retomaban en su época absurdos relatos de la Antigüedad ${ }^{13}$. Por otro lado, Voltaire entendió que para poner la historia a la altura de la nueva ciencia, era necesario escribir una historia general, «una historia de los hombres». Es decir, la "historia moderna» no podía reducirse, según el francés, a la historia de una nación privilegiada, como ocurría en los Discours sur l'histoire universelle (1681) de Jacques Bénigne Bossuet o a la superficial narración de la vida de las cortes y los reyes (cf. Voltaire, 1957, 48). Así, se interesó en sus trabajos históricos por la historia de disciplinas y lugares que hasta ese momento no habían logrado atraer en general el interés de los historiadores: la demografía, la agricultura, la economía, las costumbres, China, la India, etc.

Paolo Casini afirmaba hace algunos años que existe un paralelismo entre el método que se presenta en los Eléments de la philosophie de Newton (1738) y el

\footnotetext{
12 A propósito de la relación entre ciencia e historia en el período, véase Pomian, 1975.

13 Para una visión de conjunto sobre la escritura de la historia en el siglo XVII y en los primeros ańos del siglo XVIII, véase Guion, 2008 y Borghero, 1990.
} 
método utilizado por Voltaire en sus trabajos históricos (cf. Casini, 1980, 121$122)^{14}$. Esta interpretación resulta, no obstante, difícil de aceptar desde el momento en el que Voltaire aborda el pasado en varias ocasiones utilizando herramientas ajenas a la ciencia empírica. Así sucede, por ejemplo, cuando se ocupa de las características de las sociedades primitivas o del problema que plantea el relato de la prostitución de las damas de Babilonia, dos casos que desarrolla en un trabajo de la época de la polémica con la coterie, la Philosophie de l'histoire (1765). En su Historia, Heródoto había afirmado que en la Antigüedad para cumplir con un ritual religioso las damas de Babilonia debían prostituirse en un templo sagrado por lo menos una vez en su vida. Voltaire reacciona diciendo que es un relato falso ya que «lo que no está en la naturaleza nunca es verdadero» (Voltaire, 2004, 58) ${ }^{15}$. En cuanto a las sociedades primitivas, no duda en afirmar que tuvieron las características que en sus días tenían muchos pueblos africanos y americanos ( $c f .18)$. Pero ¿sobre qué apoya ese paralelismo? Sobre un principio a priori, a saber, la igualdad de la naturaleza humana: «la naturaleza es la misma en todas partes; así, los hombres han debido de adoptar necesariamente las mismas verdades y los mismos errores en cuanto a las cosas que más excitan la imaginación» (26). Sobre esta base realiza el paralelismo e incluso traza una historia no empírica de los pueblos primitivos. En los capítulos VI («De las costumbres y los sentimientos comunes a casi todas las naciones antiguas») y VII («De los salvajes») del libro, intenta reconstruir a priori las características de los hombres primitivos y su modo de vida, como bien advierte Myrtille Méricam-Bourdet ( $c f$. Méricam-Bourdet, 2011, 278). Así, Voltaire se arroja sobre el pasado remoto sin apoyarse en ningún tipo de evidencia, acercándose de esa manera y paradójicamente al método historiográfico de Jean-Jacques Rousseau, quien en su Discours sur l'origine et les fondements de l'inégalité parmi les hommes (1755) pedía «dejar de lado los hechos» (Rousseau, 2008, 71). En las dos situaciones mencionadas se introducen principios extra-históricos para evaluar casos históricos. Pero, estos no son los únicos casos. En el capítulo V («De la religión de los primeros hombres») afirma que todos los pueblos recorren el camino -al que llama «la marcha del

\footnotetext{
${ }^{14}$ Se puede observar una interpretación similar en el célebre trabajo de John Brumfitt, Voltaire historian (cf. Brumfitt, 1958, 98).

15 Tres ańos después, en 1768, repite el argumento en la Défense de mon oncle, un trabajo escrito para defender la Philosophie de l'histoire de los ataques de Pierre-Henri Larcher, quien había publicado en 1767 un Supplément à la Philosophie de l'histoire, donde ponía en cuestión el trabajo de Voltaire ( $c f$. Voltaire, 1984, 206). Larcher respondió ese mismo año (1767) a través de una Réponse à la Défense de mon oncle. Acerca de los críticos y las disputas de Voltaire en general, véase Kölvig y Mervaud, 1994.
} 
espíritu humano»- que los lleva desde la «razón incipiente», que corresponde al estadio de los pueblos salvajes que de manera confusa reconocen la existencia de una fuerza superior, hasta la «razón cultivada», que corresponde al estadio alcanzado por las sociedades civilizadas que reconocen la existencia de un dios «remunerador y castigador» (Voltaire, 2004, 18). Introduce así nuevamente un vector extra-histórico para evaluar la historia.

Ahora bien, ¿qué lugar ocupan las sociedades de ateos dentro de esa «marcha del espíritu humano»? En el mismo capítulo V se pregunta si se puede considerar ateos a los pueblos primitivos y responde de manera negativa. Explica que «no se los debe considerar ateos en sentido estricto, ya que no niegan al Ser Supremo [...]» (18). Algunas de esas comunidades, dice Voltaire, adoran un árbol, otras a una serpiente, sin embargo esto no justifica que se las llame ateas, simplemente, dice, desconocen la figura de Dios. ¿Qué lugar otorgar, entonces, a las sociedades dominadas por el ateísmo? No corresponde la sociedad de ateos al momento de la «razón incipiente» de los pueblos primitivos, ni tampoco al momento de la «razón cultivada» de los pueblos civilizados, que reconocen la figura de una dios remunerados y vengador. ¿Se debe concluir, entonces, que Voltaire excluye al ateísmo de la historia?

Voltaire no rechaza la posibilidad de la existencia de una sociedad de ateos. En efecto, en la entrada ATHÉIsme que redactó algunos años después, en 1770, para las Questions sur l'Encyclopédie acepta la posibilidad de una sociedad que tenga esas características. En una discusión que entabla en esa entrada con Pierre Bayle, quien en sus Pensées diverses sur la comète (1682) había sostenido que una sociedad de ateos no solo era posible, sino que además podía llegar a ser mejor que otras sociedades ( $c f$. Bayle, 1704, 327 y ss.), Voltaire afirma que una sociedad de ateos o dominada por el ateísmo es posible -en la versión de esa entrada redactada algunos años antes para el Dictionnaire philosophique presenta, incluso, un ejemplo histórico: la república romana ( $c f$. Voltaire, 1964b, 56)-, pero niega que pueda ser una buena sociedad: «los lobos viven así», exclama al referirse a las sociedades «sin dios». No acepta, incluso, que una sociedad de ese tipo sea realmente una sociedad: «una sociedad no es simplemente la unión de un montón de bárbaros antropófagos», concluye (Voltaire, 1770, 288).

Voltaire no niega la posibilidad de que pueda formarse en la historia una sociedad de ateos. Reconoce, incluso, un caso histórico. No acepta, sin embargo, que se trate de una verdadera sociedad. Dado que para Voltaire la sociedad 
es «natural» (cf. Voltaire, 2004, 34), una sociedad de seres «sin dios» constituye una especie de orden «desnaturalizado». Como ya se ha seńalado, en 1770 califica el Système de la Nature de Holbach, que promulgaba el ateísmo, como «un pecado contra la naturaleza» (Voltaire, 1833b, 481). Como los antropófagos, las sociedades que han sacrificado sangre humana a los dioses o los seres que viven en soledad, una sociedad de ateos, sería algo extraño, excepcional, contrario a lo que marca la naturaleza, una idea que tiene un papel normativo en la filosofía de Voltaire ( $c f$. Voltaire, 2004, 35, 45). De esta manera, si bien no rechaza la existencia en la historia de sociedades de ateos, les otorga un lugar marginal y negativo en la marcha del espíritu humano.

\section{Conclusiones}

Las críticas al materialismo ateo de la coterie holbachique, que, como se puede observar en este trabajo, se desarrollan en diferentes terrenos (filosofía de la historia, moral, gnoseología y metafísica), resultan problemáticas en la obra de Voltaire, en la medida en que lo llevan, como creemos haber demostrado en (3), a poner un límite en su lucha contra el infame y la campaña por la tolerancia, pero también a aceptar por momentos una idea de dios - «un Dios que castiga y perdona» (Voltaire, 1833b, 160) - contraria a la que domina su filosofía. Con respecto a este último aspecto, René Pomeau en su célebre trabajo La religion de Voltaire, que es aún la obra de referencia para los estudios acerca de la religión en la obra de Voltaire, afirma que la idea de un Dios que invade la vida de los hombres es una obsesión latente desde la infancia en la vida del filósofo y que reaparece en su vida en ciertos momentos de pesimismo, como el de la muerte de la marquesa Émilie du Châtelet ( $c f$. Pomeau, 1969, 247-248 y 415). Si se acepta esta interpretación, entendemos, se corre el riesgo de reducir el tema al plano psicológico o biográfico. Como se puede observar en (4), ese tipo de divinidad corresponde en la Philosophie de l'histoire a las sociedades en las que se plasma el máximo desarrollo del espíritu humano. Parece, por lo tanto, que no se debe minimizar la injerencia de la idea de un Dios que controla a los hombres en la filosofía de Voltaire.

A partir de lo antes dicho se puede comprender el sentido de la frase de Voltaire acerca de la Compañía de Jesús con la que se abre este trabajo. La expulsión de Francia de los jesuitas, que se sumaba a la que ya habían sufrido 
tiempo atrás los protestantes ${ }^{16}$-como se advierte en la carta a d'Alembert ya mencionada-, dejaba el campo libre a los "fanáticos jansenistas», que subyugarían a los franceses al no encontrar ningún freno (cf. Voltaire, 1832, 399). La preocupación por el ateísmo llevó a Voltaire en esa época y paradójicamente, ya que había comenzado en 1761 una virulenta campaña contra la religión revelada, a moderar sus criticas contra éstas, inquietándose solamente por sus excesos: "un cura ruin inspira desprecio, un mal cura, horror, en cambio, un buen cura, dulce, piadoso, con un espíritu libre de supersticiones, caritativo, tolerante, es un hombre que debe ser apreciado y respetado. Tú temes el abuso y también yo. Unámonos para combatirlo, pero no condenemos el uso de la religión cuando es útil a la sociedad», dice en la entrada Dieu de las Questions sur l'Encyclopédie (Voltaire, 1771, 301). Es decir, Voltaire revaloriza en pleno combate contra el infame algunos aspectos de las religiones reveladas, lo cual genera tensiones en sus obras y proyectos. En ese marco se inscribe su posición moderada frente a la expulsión de la Compañía de Jesús.

Por otra parte, el análisis de las críticas al ateísmo, puso de relieve, como se puede observar en (4), los límites con los que choca su proyecto historiográfico, en la medida en que los principios a priori que introduce lo llevan a no observar en muchas ocasiones los criterios establecidos para la escritura de una «historia científica».

\section{Agradecimientos}

Este trabajo se ha realizado en el marco del proyecto "WORLDBRIDGES: Philosophy of History and Globalisation of Knowledge. Cultural Bridges

${ }^{16}$ Las guerras de religión habían terminado en Francia en 1598, tras la firma del Edicto de Nantes por el rey Enrique IV, que otorgaba a los protestantes una libertad de culto limitada. El Edicto de Fontainebleau, firmado por Luis XIV en 1685 había revocado el Edicto de Nantes y había prohibido el protestantismo en Francia. Como consecuencia del nuevo edicto se intentaba convertir por la fuerza a los protestantes que habitaban en terreno francés. Algunos emigraban, otros practicaban el culto de manera clandestina a pesar de su conversión. Aquellos que eran descubiertos en asambleas clandestinas recibían severas penas, los hombres eran condenados a muerte o enviados a trabajar en galeras, las mujeres, sometidas a actos humillantes. El conflicto se extendió hasta 1711, pero los actos de intolerancia recorrieron todo el siglo XVIII francés. Para una visión de conjunto acerca del problema de la intolerancia en el siglo XVIII, véase el ya mencionado trabajo colectivo editado por Grell y Porter, 2000. 
Between Europe and Latin America”, Marie Curie International Research Staff Exchange Scheme (F7-PEOPLE-2013-IRSES: 612644).

\section{Bibliografía}

Barnett, J. (2003). The Enlightenment and Religion: the Myths of Modernity. Manchester: Manchester University Press.

Bayle, P. (1704). Pensées diverses sur la comète. Róterdam: Reinier Leers.

Borghero, C. (1990). «Les philosophes face à l'histoire: quelques discussions sur la connaissance historique aux XVII ${ }^{e}$ et XVIII ${ }^{e}$ siècles». Pratiques et concepts de l'histoire en Europe, $X V I^{e}-X V I I I^{e}$ siècles. Eds. Ch. Grell y J.-M. Dufays. Paris: Presses de l'Université de Paris-Sorbonne, pp. 73-83.

Brumfitt, J. (1958). Voltaire historian. Oxford: Oxford University Press.

CASINI, P. (I980). «Progrès de la raison et progrès des sciences chez les encyclopédistes». L'histoire au dix-huitième siècle. Aix-en-Provence: EDISUD, pp. 121-122.

Cordemoy, G. (I691). «Ce qu'on doit observer en écrivant l'Histoire». Divers traitez (sic) de métaphysique, d'histoire, et de politique. Paris: Coignard.

Curran, M. (2012). Atheism, Religion and Enlightenment in Pre-Revolutionary Europe. Rochester: Boydell Press.

D’Alembert, J. (1765). Sur la destruction des jésuites en France. Edinbourg: Balfour.

Diderot, D. (1877). «Correspondance». Euvres complètes de Diderot XIX. Eds. J. Assézat y M. Tourneux. Paris: Garnier Frères.

Ferret, O. (2007). La Fureur de nuire: échanges pamphlétaires entre philosophes et antiphilosophes (1750-1770). Oxford: Voltaire Foundation.

GaY, P. (1966). The Enlightenment: the Rise of Modern Paganism. New York: Alfred A. Knopf.

Grell, P. y Porter, R. (eds.) (2000). Toleration in Enlightenment Europe. Cambridge: Cambridge University Press.

Grimm et al. (1879). Correspondance littéraire, philosophique et critique. Ed. M. Tourneaux. Paris: Garnier Frères, vol. 7.

Guion, B. (2008). Du bon usage de l'histoire: histoire, morale et politique à l'âge classique. Paris: Honoré Champion.

HaAkonssen, K. (2006). Enlightenment and Religion: Rational Dissent in EighteenthCentury Britain. Cambridge: Cambridge University Press. 
Holbach (2008). El cristianismo al descubierto. Trad. J. Fortanet y R. Martínez González. Pamplona: Laetoli.

Kölvig, U. y Mervaud, Ch. (eds.) (1994). Voltaire et ses combats. Oxford/Paris: Voltaire Foundation.

LAMBERT, G. (1992). «Antoine Adam, Voltaire's Jesuit in residence». Studies on Voltaire and the Eighteenth Century, vol. 302, pp. 23-67.

Magnan, A. (1986). Voltaire en Prusse, 1750-1753. Oxford: Voltaire Foundation.

Masseau, D. (2000). Les ennemis des philosophes. L'antiphilosophie au temps des Lumières. Paris: Albin Michel.

Méricam-Bourdet, M. (2011). «Les inflexions du discours historique voltairien sur l'origine dans les années 1760: le rôle de Rousseau». Revue Voltaire, pp. 275-285.

Mortier, R. (1994). "Ce maudit Système de la nature». Voltaire et ses combats. Eds. U. Kölvig y CH. Mervaud. Oxford/Paris: Voltaire Foundation.

Pomeau, R. (200I). «Voltaire et $\mathrm{M}^{\mathrm{me}} \mathrm{du}$ Châtelet à Cirey: amour et travail». Cirey dans la vie intellectuelle: La réception de Newton en France. Ed. F. GANDT. Oxford: Voltaire Foundation, pp. 9-15.

(1969). La religion de Voltaire. Paris: Nizet.

Pomian, K. (1975). «L'histoire de la science et l'histoire de l'histoire». Annales. Économies, Sociétés, Civilisations, vol. 5, pp. 935-952.

Rousseau, J.-J. (2008). Discurso sobre el origen y los fundamentos de la desigualdad entre los hombres. Trad. Vera Waksman. Buenos Aires: Prometeo.

Sorkin, D. (2008). The Religious Enlightenment: Protestants, Jews, and Catholics from London to Vienna. Princeton: Princeton University Press.

Trousson, R. (2009). «Tolérance et fanatisme selon Voltaire et Rousseau». Rousseau and l'Infâme. Religion, toleration and fanaticism in the Age of Enlightenment. Ed. O. Mostefai y J.-T. Scott. Amsterdam: Rodopi, pp. 23-64.

(1993). Histoire de la libre pensée des origines à 1789. Bruxelles: Espace de liberté.

Voltaire (1765). «Histoire». Encyclopédie ou Dictionnaire raisonné des sciences, des arts et des métiers. Ed. D. Diderot y J. D’Alembert. Paris: Briasson, David, Le Breton, Durand, vol. 8, pp. 220-225.

(1770). Questions sur l'Encyclopédie. Ginebra: Cramer, vol. 1.

(1771). Questions sur l'Encyclopédie. Ginebra: Cramer, vol. 4.

(1832). «Correspondance». CEuvres de M. Arouet de Voltaire LXI. Ed. M. Beuchot. Paris: Lefevvre / Firmin Didot Frères. 
(1833a). «Correspondance». Euvres de M. Arouet de Voltaire LXIII. Paris: Lefèvre / Firmin Didot Frères.

(1833b). «Correspondance». CEuvres de M. Arouet de Voltaire LXV. Paris: Lefèvre / Firmin Didot Frères.

(1879a). «Homélies», Euvres complètes de Voltaire XXVI. Ed. L. Moland. Paris: Garnier.

(1879b). «Dieu et les hommes». Euvres complètes de Voltaire XXVIII. Paris: Garnier.

(1879c). «Questions sur les miracles». Euvres complètes de Voltaire XXV. Paris: Garnier.

(1879d). «Traité de métaphysique». CEuvres complètes de Voltaire XXII. Paris: Garnier.

(1957). «Nouvelles considérations sur l'histoire». Euvres historiques. Ed. R. Pomeau, Paris: Gallimard.

(1964a). Lettres philosophiques. Ed. R. Pomeau. Paris: Flammarion.

(1964b). Dictionnaire philosophique. Ed. R. Pomeau. Paris: Garnier.

(1984) «La défense de mon oncle». Euvres complètes de Voltaire / Complete Works of Voltaire. Ed. J.-M. Moureaux. Oxford: The Voltaire Foundation.

(2004). Filosofía de la historia. Trad. M. Caparrós. Madrid: Tecnos.

(2007). Tratado sobre la tolerancia. Trad. M. Armiño. Madrid: Austral.

Enviado: 10/08/2015

Aceptado: 12/11/2015

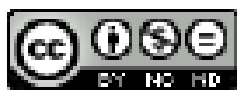

ENDOXA está bajo una licencia de Creative Commons Reconocimiento-NoComercial-SinObraDerivada 4.0 Internacional 
